\title{
Mulberry Anthocyanin Extract Ameliorates Oxidative Damage in HepG2 Cells and Prolongs the Lifespan of Caenorhabditis elegans through MAPK and Nrf2 Pathways
}

\author{
Fujie Yan, ${ }^{1,2,3}$ Yushu Chen, ${ }^{1,2,3}$ Ramila Azat, ${ }^{1,2,3}$ and Xiaodong Zheng ${ }^{1,2,3}$ \\ ${ }^{1}$ Department of Food Science and Nutrition, Zhejiang University, Hangzhou 310058, China \\ ${ }^{2}$ Zhejiang Key Laboratory for Agro-food Processing, Zhejiang University, Hangzhou 310058, China \\ ${ }^{3}$ Fuli Institute of Food Science, Zhejiang University, Hangzhou 310058, China \\ Correspondence should be addressed to Xiaodong Zheng; foodbiotech@zju.edu.cn
}

Received 16 January 2017; Revised 31 March 2017; Accepted 11 May 2017; Published 21 June 2017

Academic Editor: Gabriele Saretzki

Copyright (@ 2017 Fujie Yan et al. This is an open access article distributed under the Creative Commons Attribution License, which permits unrestricted use, distribution, and reproduction in any medium, provided the original work is properly cited.

\begin{abstract}
Mulberry anthocyanins possess many pharmacological effects including liver protection, anti-inflammation, and anticancer. The aim of this study was to evaluate whether mulberry anthocyanin extract (MAE) exerts beneficial effects against oxidative stress damage in HepG2 cells and Caenorhabditis elegans. In vitro, MAE prevented cytotoxicity, increased glucose consumption and uptake, and eliminated excessive intracellular free radicals in $\mathrm{H}_{2} \mathrm{O}_{2}$-induced cells. Moreover, MAE pretreatment maintained Nrf2, HO-1, and p38 MAPK stimulation and abolished upregulation of p-JNK, FOXO1, and PGC-1 $\alpha$ that were involved in oxidative stress and insulin signalling modulation. In vivo, extended lifespan was observed in C. elegans damaged by paraquat in the presence of MAE, while these beneficial effects were disappeared in pmk-1 and daf-16 mutants. PMK-1 and SKN-1 were activated after exposure to paraquat and MAE suppressed PMK-1 activation but enhanced SKN-1 stimulation. Our findings suggested that MAE recovered redox status in HepG2 cells and C. elegans that suffered from oxidative stress, which might be by targeting MAPKs and Nrf2.
\end{abstract}

\section{Introduction}

Generation of excessive reactive oxygen species (ROS) results in oxidative stress that disturbs intracellular redox status homeostasis and induces cell apoptosis or death [1]. Prolonged oxidative stress impairs normal functions of cells, tissues, and organs, potentially accelerating the process of some diseases such as cancer, hepatopathy, diabetes, and obesity [2]. Therefore, it seems that oxidative stress becomes a critical target in the prevention of chronic diseases.

Nuclear factor erythroid 2-related factor 2 (Nrf2), a short-lived protein, allows adaption and survival under stress by regulating expression of genes and proteins with diverse cytoprotective functions including anti-inflammatory, antioxidant, and detoxification enzymes. Kelch-like ECHassociated protein 1 (Keap1) is a negative regulator of Nrf2, contributing to its degradation under normal conditions. Keap1-Nrf2 interactions are disrupted by shear stress or other physiological stimuli, causing nuclear accumulation of Nrf2, leading to the transcription of its target genes such as heme oxygenase-1 (HO-1), g-glutamate-cysteine ligase (GCL), and $\mathrm{NAD}(\mathrm{P}) \mathrm{H}$ :quinone oxidoreductase 1 (NQO1) $[3,4]$. HO-1 acts as a rate-limiting enzyme in heme metabolism, and GCL catalyzes the first and ratelimiting step of GSH biosynthesis [5, 6]. NQO1 protects cells from oxidative damage through catalyzing quinone detoxification [7]. Therefore, Nrf2 plays a crucial role in cellular redox homeostasis, mitochondrial health, and fatty acid oxidation. Moreover, MAPKs can affect Nrf2 activity and are involved in oxidative stress regulation [8-10].

Anthocyanins belong to the family of flavonoids but are different from other flavonoids because of their flavylium cation structures. They occur in berries, deep-color fruit, and grains that are well represented in the human diet. Mulberry fruit, which is abundant in water soluble anthocyanins such as cyanidin-3-glucoside and cyanidin-3- 
rutinoside, has been traditionally used in Chinese medicines due to its pharmacological effects [11]. Mulberry possesses many beneficial actions including antioxidation, anti-inflammation, liver protection, and anticancer either in cultured cells or in animal models, which is partly associated with its capacity of free radical scavenging [12]. Attributed to the special molecular structure, anthocyanins show great antioxidant properties in in vitro analyses such as ferric reducing antioxidant potential (FRAP) and oxygen radical absorbance (ORAC) [13]. Although studies reported that the bioavailability of anthocyanins was low, which meant tiny related substance could be detected in plasma and urine [14], anthocyanin administration indeed obviously increased plasma antioxidant ability in Wistar rats, suggesting that some antioxidant compounds in blood are activated after anthocyanin digestion and absorption [15]. Protective roles of mulberry anthocyanins in the liver have been reported in both cells and animals, which are partly connected with oxidative alleviation [16-18]. Nevertheless, researches about protective effectiveness and possible mechanisms at molecular levels of MAE on cells and C. elegans under conditions of oxidative stress are insufficient.

In this study, in vitro, we aimed to investigate MAEbased protection against $\mathrm{H}_{2} \mathrm{O}_{2}$-induced oxidative stress in HepG2 cells and confirm whether this effect depends upon MAPK and Nrf2 modulation. Furthermore, we estimated the impact of MAE on paraquat-mediated oxidative injury in Caenorhabditis elegans in vivo. Results from this model organism may be more relevant for an evaluation of the biological actions of anthocyanins in humans.

\section{Material and Methods}

2.1. Preparation of MAE. Mulberry anthocyanins were isolated and purified as previously described [19]. Briefly, mulberry fruit (Morus alba L.) was purchased from the local market (Hangzhou, China) and extracted with a 3fold volume of $95 \%$ ethanol containing $1 \% \mathrm{HCl}$ for $24 \mathrm{~h}$ at $4^{\circ} \mathrm{C}$. Filtered fluid was evaporated at $38^{\circ} \mathrm{C}$, and then, the concentrates were loaded onto an equilibrated AB-8 macroporous resin column orderly eluted with $1 \%$ formic acid in $80 \%$ methanol for further purification. MAE was obtained by lyophilization and stored at $-80^{\circ} \mathrm{C}$ before use.

2.2. Determination of Anthocyanins, Total Proteins, and Total Soluble Carbohydrate Contents in MAE. Separation of anthocyanins was conducted on Promosil C18 column $(4.6 \times 250 \mathrm{~mm}, 5 \mu \mathrm{m})$ using an HPLC instrument (Thermo UltiMate 3000). Anthocyanin standards (J\&K Chemicals, China) were used for quantitative determination. The contents of total proteins and total soluble carbohydrate in MAE were determined using the Bradford and the phenolsulfuric acid method, respectively.

2.3. Cell Culture and Treatments. HepG2 cells were cultured in DMEM supplemented with $10 \%$ fetal bovine serum, $100 \mathrm{IU} / \mathrm{mL}$ penicillin, and $100 \mu \mathrm{g} / \mathrm{mL}$ streptomycin at $37^{\circ} \mathrm{C}$ in a 5\% $\mathrm{CO}_{2}$ atmosphere. After reaching 70-80\% confluence, the cells were washed with PBS twice and incubated in the absence or presence of MAE with different concentrations for $24 \mathrm{~h}$. The powder of MAE was dissolved in PBS buffer to produce the stock solution $(10 \mathrm{mg} / \mathrm{mL})$ and was freshly diluted in media without FBS to a certain concentration. And then, $300 \mu \mathrm{M} \mathrm{H}_{2} \mathrm{O}_{2}$ was added into the media for another $4 \mathrm{~h}$. Cells without $\mathrm{H}_{2} \mathrm{O}_{2}$ treatment were used as the negative control, and cells treated with glutathione $\mathrm{GSH}$, $1 \mathrm{mM}$ ) were used as the positive control.

2.4. MTT Assays. Cells were seeded into a 96-well plate, and MTT diluted with PBS at a final concentration of $0.5 \mathrm{mg} / \mathrm{mL}$ was added to each well after treatments. After $4 \mathrm{~h}$ of incubation at $37^{\circ} \mathrm{C}$, the formazan precipitate was dissolved in $150 \mu \mathrm{L}$ DMSO and the absorbance was measured at $570 \mathrm{~nm}$ with a spectrophotometer [20]. In our studies, the treatment of HepG 2 cells with MAE at $100 \mu \mathrm{g} / \mathrm{mL}$ produced no detectable cell toxicity, which was consistent with previous research [21-23].

2.5. Glucose Consumption and Uptake Assays. The glucose consumption was estimated by the method of Lv et al. [24] with modification. Cells were seeded into a 96-well plate with five wells left as blanks. After $\mathrm{H}_{2} \mathrm{O}_{2}$ treatment, all media were removed and changed to the same. $24 \mathrm{~h}$ later, the glucose in the medium of each well was measured by a commercially available kit using the glucose oxidase method. $2 \mu \mathrm{L}$ medium was added into $200 \mu \mathrm{L}$ reaction agents, incubated for $20 \mathrm{~min}$ at $37^{\circ} \mathrm{C}$, and then detected at $505 \mathrm{~nm}$ by a microplate reader (Molecular Devices, USA). Glucose consumption was calculated by the glucose concentrations in blank wells (no cell) minus glucose concentrations in plated wells. The MTT assay was used to adjust the glucose consumption. There were five replicates for each treatment and the experiment was repeated three times.

Cells with different treatments were exposed to $0.1 \mathrm{mM}$ $2-\mathrm{NBDG}$ and $100 \mathrm{nM}$ insulin for $30 \mathrm{~min}$ at $37^{\circ} \mathrm{C}$. Images were obtained using identical acquisition settings on a fluorescence microscope [25].

2.6. ROS and Superoxide Visualization. Cells were pretreated with MAE or GSH for $24 \mathrm{~h}$, and then, $300 \mu \mathrm{M} \mathrm{H}_{2} \mathrm{O}_{2}$ was added into the media for another $4 \mathrm{~h}$. After that, all media were removed and changed to serum-free media loaded with $\mathrm{H}_{2}$ DCFDA (for ROS measurement) or DHE (for superoxide determination) at $10 \mu \mathrm{M}$ for $30 \mathrm{~min}$. Images were observed under a fluorescence microscope at identical exposure time. Densitometry analysis was performed using the Image-Pro Plus 6.0 software.

2.7. C. elegans Strains and Exposure. Strain N2 was provided by Dr. Du (Zhejiang University, China), and mutants CF1038 [daf-16(mu86)I], SPC167 [dvIs19 III; skn-1(lax120) IV], and AY102 [pmk-1(km25) IV; acEx102] were kindly provided by Dayong Wang (Southeast University, China). The strain was maintained at $20^{\circ} \mathrm{C}$ on a standard nematode growth medium (NGM) with E. coli OP50 as food resources.

Synchronized young adult worms were grown in NGM with FudR (5-fluoro-2'-deoxy- $\beta$-uridine, $50 \mu \mathrm{g} / \mathrm{mL}$ ) and OP50 containing different agents during the whole life span. A total of 30-40 young adults were cultured on each NGM 


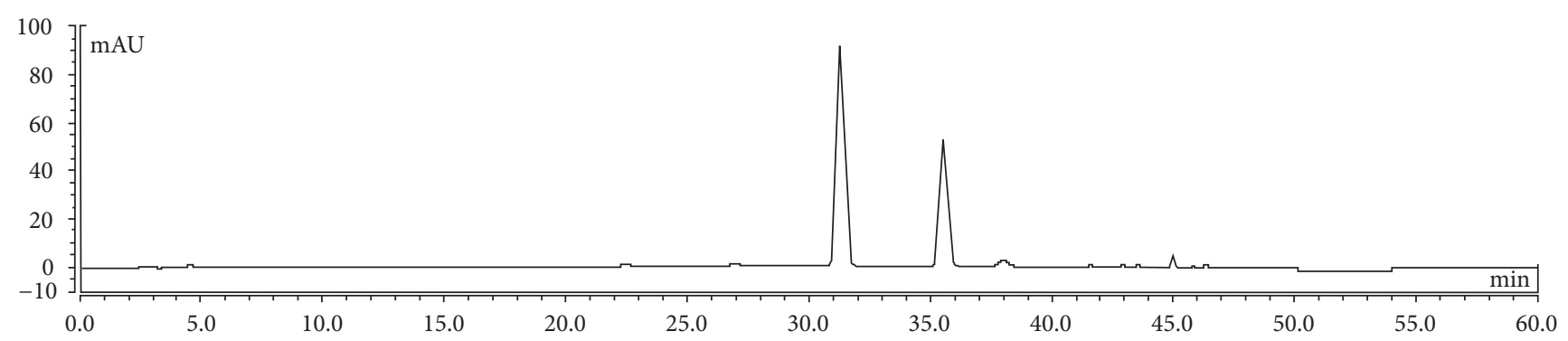

FIGURE 1: Identification and quantification of anthocyanins in MAE by HPLC analysis. The mobile phase A was $8.5 \%$ formic acid aqueous solution and the mobile phase B was formic acid/acetonitrile/methanol/water $(8.5: 22.5: 22.5: 41.5, v / v / v / v)$. A linear gradient program: 0 $35 \mathrm{~min}$ from 7 to $25 \% \mathrm{~B}, 35-45 \mathrm{~min}$ from 25 to $65 \% \mathrm{~B}, 45-46 \mathrm{~min}$ from 65 to $100 \% \mathrm{~B}$, and $46-50 \mathrm{~min} 100 \% \mathrm{~B}$. The flow rate was $1.0 \mathrm{~mL} /$ min and the absorption spectrum was recorded at $535 \mathrm{~nm}$. The column was operated at a temperature of $30^{\circ} \mathrm{C}$. Three replicates were performed in the analysis.

and worms were counted every other day. Worms that did not move when gently touched with a platinum wire were considered dead. The whole experiments were repeated three times.

2.8. Analysis of Intracellular Lipofuscin and MDA. Worms were raised in NGM containing FudR and OP50 with or without paraquat and MAE. On the 10th day of adulthood, the intestinal autofluorescence by lipofuscin was analyzed. Twenty randomly selected worms from treatments were mounted onto microscope slides coated with $1 \%$ agarose and anesthetized with $5 \mathrm{mM}$ levamisole. The autofluorescence of lipofuscin was captured with a fluorescence microscope (Leica, Wetzlar, Germany) using the DAPI filter set [26]. Densitometry analysis was performed using the Image-Pro Plus 6.0 software.

Worms with different treatments were washed from plates by M9 buffer and were ground in liquid nitrogen. Malondialdehyde (MDA) contents were determined by commercial kits (Nanjing Jiancheng, China).

2.9. Quantitation of PMK-1 and SKN-1 Expressions. Age-synchronized worms were treated with the MAE on the first day after hatching for $48 \mathrm{~h}$ and were then exposed to $1 \mathrm{mM}$ paraquat for $24 \mathrm{~h}$. After induction, expressions of PMK-1 and SKN-1 were measured directly through measuring the fluorescence intensity of the reporter protein GFP by fluorescence microscopy.

2.10. RNA Isolation and $q P C R$ Analysis. Total RNA from worms was extracted using an RNAiso Plus kit (code D9108B, TaKaRa, Japan) according to the manufacturer's instructions. Real-time PCR was performed using the SYBR Green Kit (Roche) on the ABI Step One RT-PCR system. Primers designed with Primer Blast were listed in Table S1 available online at https://doi.org/10.1155/2017/7956158. GPD-1 was used for the reference gene.

2.11. Western Blot. Total protein extracts were prepared using the WB/IP lysis buffer (Beyotime Biotechnology, China). Cytoplasmic and nuclear protein extracts were prepared using a commercial kit (Sangon, China) according to the manufacturer's instructions. Equivalent amounts of protein from cell homogenates were subjected to SDS-PAGE and
TABLE 1: Quantification of anthocyanins, protein, and total soluble carbohydrate contents in MAE.

\begin{tabular}{lcc}
\hline Fraction & $\begin{array}{c}\text { Retention time } \\
(\mathrm{min})\end{array}$ & $\begin{array}{c}\text { Content } \\
(\mathrm{mg} / \mathrm{g})\end{array}$ \\
\hline Cyanidin-3-glucoside & 31.2 & $472 \pm 9.23$ \\
Cyanidin-3-rutinoside & 35.7 & $273 \pm 5.12$ \\
Pelargonidin-3-glucoside & 38.0 & $14 \pm 0.29$ \\
Protein & - & $72 \pm 2.8$ \\
Total soluble carbohydrate & - & $86 \pm 3.6$ \\
\hline
\end{tabular}

Anthocyanin concentrations were determined by HPLC analysis. Protein content was determined by the Bradford method and measured at $595 \mathrm{~nm}$. Total soluble carbohydrate was determined by the phenol-sulfuric acid method and measured at $490 \mathrm{~nm}$. All values are mean \pm SD. Three replicates were performed in the analysis.

transferred to PVDF membranes. Membranes were probed with primary antibodies against p-JNK, JNK, p-p38, and p38 (Beyotime Biotechnology, China) and Nrf2, HO-1, FOXO1, and PGC-1 $\alpha$ (Abcam). Membranes were detected with horseradish peroxidase-conjugated secondary antibodies using the ECL detection system. $\beta$-Actin (Beyotime Biotechnology, China) was used as the loading control. Densitometry analysis was performed using the Image-Pro Plus 6.0 software.

2.12. Statistical Analyses. Data are means \pm SD. Statistical analyses of the data were performed with SPSS for Windows Version 11.5. One-way ANOVA analyses and Duncan's multiple-range test were used to detect statistical significances. The unpaired $t$-test was used to assess the significant differences between groups and differences were considered significant when $p<0.05$.

\section{Results}

3.1. Determination and Analysis of Compositions in the Extract. HPLC analysis showed that the contents of anthocyanins in MAE were cyanidin-3-glucoside (47.2\%), cyanidin3 -rutinoside (27.3\%), and pelargonidin-3-glucoside (1.4\%). Besides, there were $7.2 \%$ protein and $8.6 \%$ total carbohydrate in the extract (Figure 1 and Table 1). 


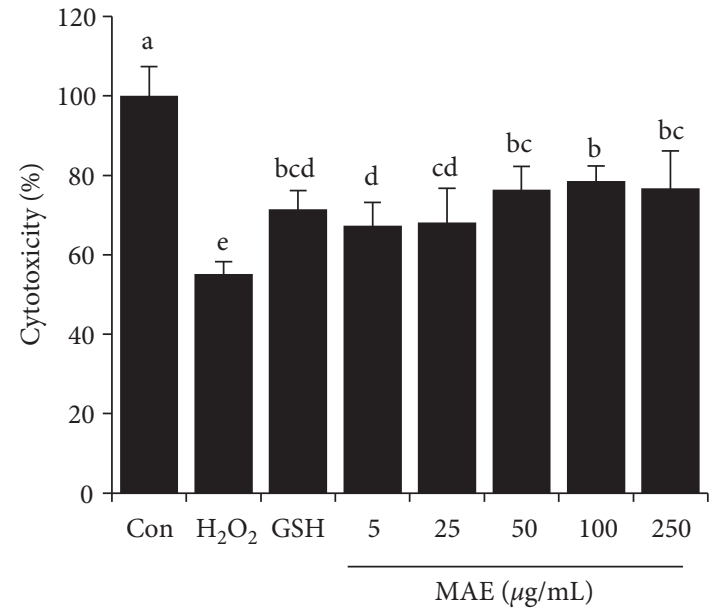

(a)

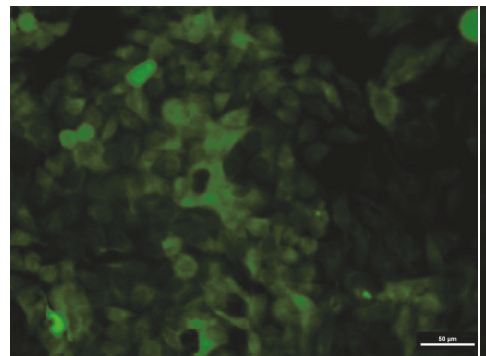

(A)

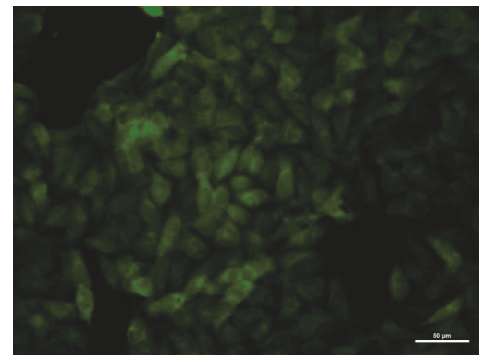

(C)

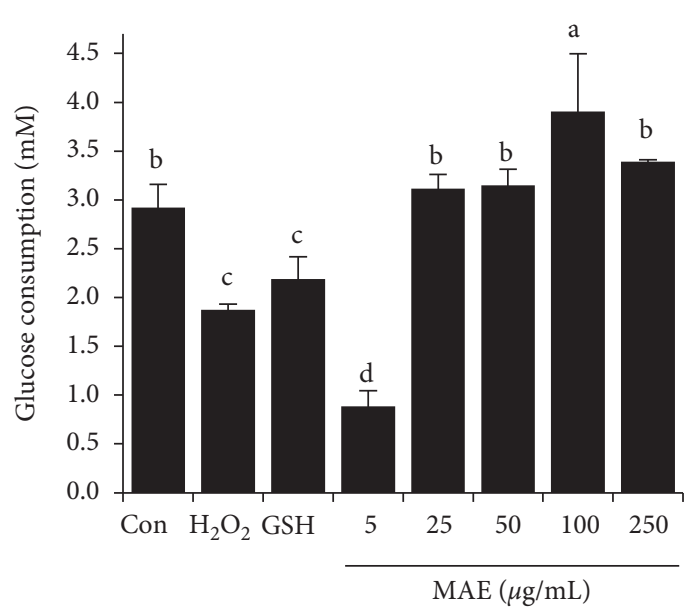

(b)

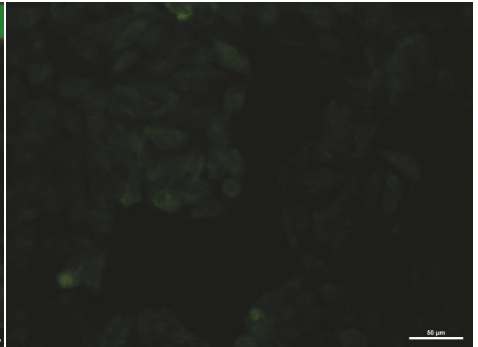

(B)

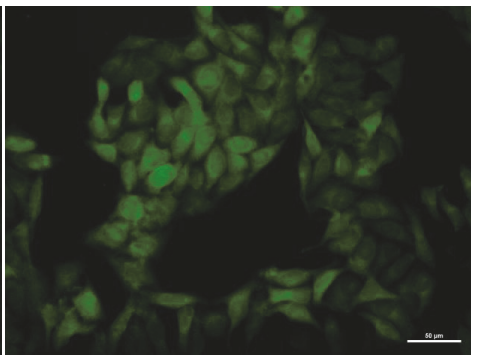

(D)

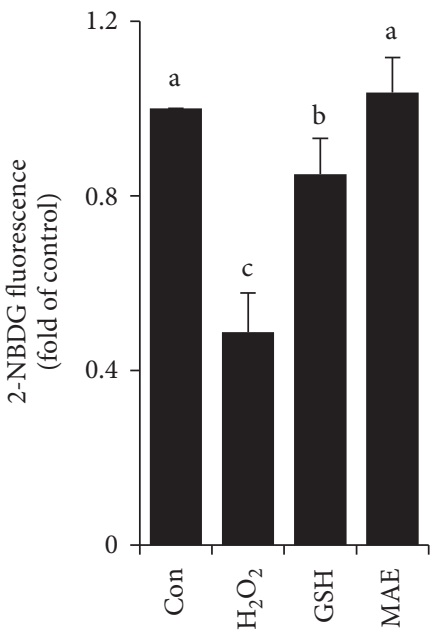

(c)

Figure 2: Effect of MAE on cytoprotection and glucose metabolism in $\mathrm{H}_{2} \mathrm{O}_{2}$-induced HepG2 cells. (a) Cell viability analyzed by MTT assays; (b) HepG2 cells were incubated with 5, 25, 50, 100, and $250 \mu \mathrm{g} / \mathrm{mL}$ MAE or $1 \mathrm{mM} \mathrm{GSH}$ for $24 \mathrm{~h}$ and were exposed to $\mathrm{H}_{2} \mathrm{O}_{2}(300 \mu \mathrm{M}, 4 \mathrm{~h}$ ). After that, all media were removed and changed to the same for glucose consumption measurement. Vertical lines represent standard deviations of five replicates. (c) Uptake of 2-NBDG into HepG2 cells. (A) control, (B) $\mathrm{H}_{2} \mathrm{O}_{2}(300 \mu \mathrm{M}, 4 \mathrm{~h}),(\mathrm{C}) \mathrm{GSH}$ (1 mM), and (D) MAE $(100 \mu \mathrm{g} / \mathrm{mL})$. Densitometry analysis was performed using the Image-Pro Plus 6.0 software. Values with different letters above are significantly different, $p<0.05$, one-way ANOVA test.

3.2. MAE Abolished Both Glucose Consumption and Uptake Decreases in $\mathrm{H}_{2} \mathrm{O}_{2}$-Induced HepG2 Cells. As shown in Figure 2(a), $\mathrm{H}_{2} \mathrm{O}_{2}$ incubation led to a significantly reduced cell viability, which was obviously recovered by GSH or MAE pretreatment, and the protective effect was dosedependent around a range of concentrations. Compared to the control, an obvious decrease in glucose consumption and uptake was investigated in cells with $300 \mu \mathrm{M} \mathrm{H}_{2} \mathrm{O}_{2}$ exposures for $4 \mathrm{~h}$, indicating that insulin resistance happened in cells that suffered from oxidative damage. However, MAE significantly restored the glucose consumption by $65.6 \%$, $67.6 \%, 107.8 \%$, and $80.3 \%$ at $25,50,100$, and $250 \mu \mathrm{g} / \mathrm{mL}$, respectively. GSH, as an antioxidant agent, also showed a recovery capacity on glucose consumption. Additionally, both GSH and MAE were able to avoid the inhibited glucose uptake caused by $\mathrm{H}_{2} \mathrm{O}_{2}$, showing similar results with glucose consumption (Figures 2(b) and 2(c)).

3.3. MAE Inhibited $\mathrm{H}_{2} \mathrm{O}_{2}$-Induced ROS and $\mathrm{O}_{2}^{-}$Generation in HepG2 Cells. An increase in antioxidant ability to inhibit $\mathrm{ROS}$ and $\mathrm{O}_{2}^{-}$generation is one of the strategies to prevent hepatotoxicity triggered by oxidative stress. Basal ROS and $\mathrm{O}_{2}^{-}$levels were increased by approximately $60 \%$ and $40 \%$, respectively, in $\mathrm{H}_{2} \mathrm{O}_{2}$-treated HepG2 cells, while 


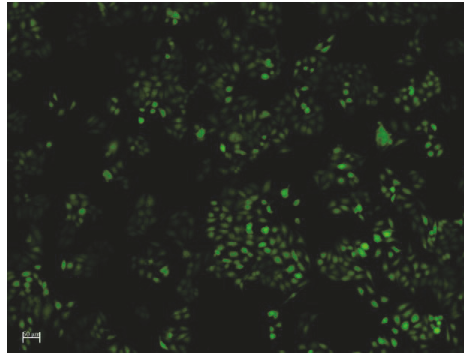

(A)

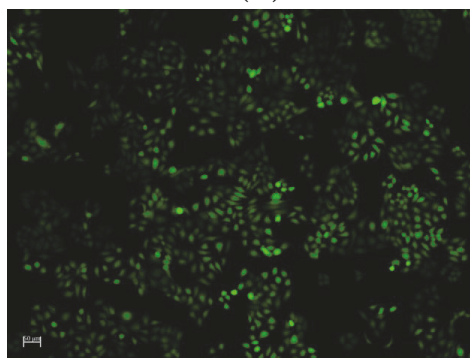

(C)

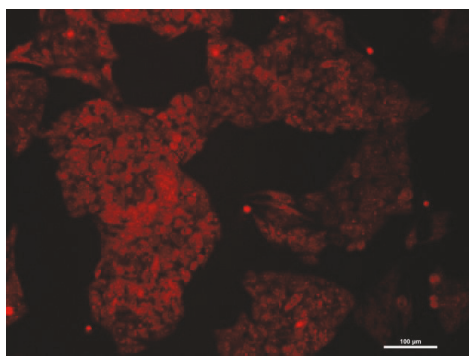

(A)

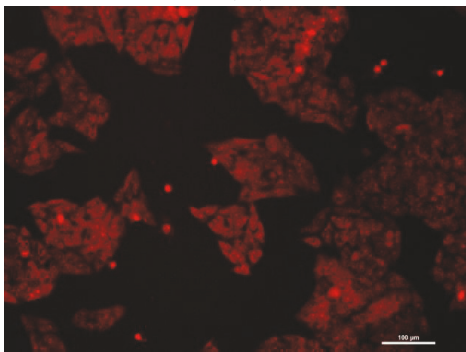

(C)

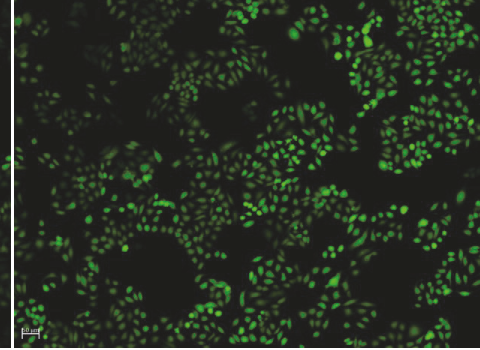

(B)

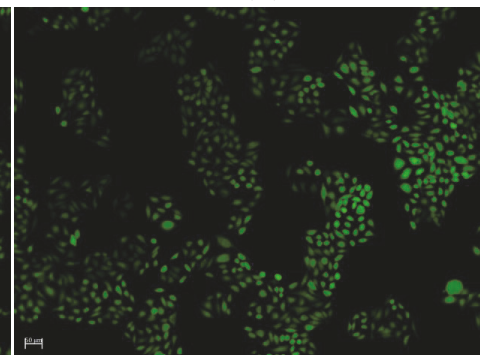

(D)

(a)

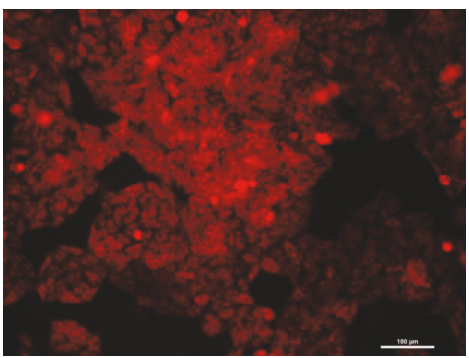

(B)

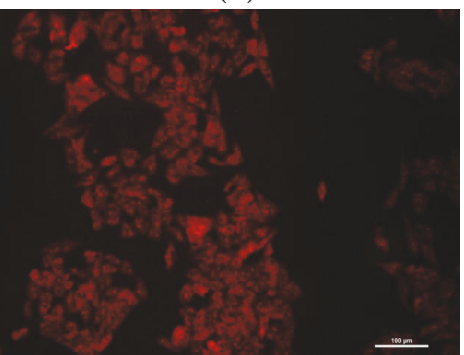

(D)
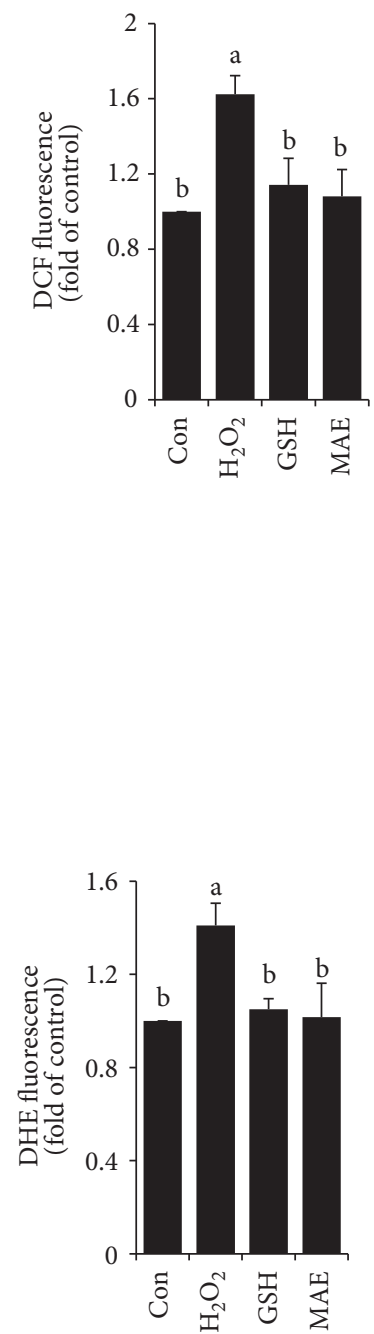

(b)

Figure 3: MAE reduced $\mathrm{H}_{2} \mathrm{O}_{2}$-induced intracellular ROS and $\mathrm{O}_{2}^{-}$levels in HepG2 cells. Cells with different treatments were incubated with $\mathrm{H}_{2}$ DCFDA or DHE for (a) ROS and (b) $\mathrm{O}_{2}^{-}$analysis. The results are shown as representative microscopic scans: (A) control, (B) cells induced by $\mathrm{H}_{2} \mathrm{O}_{2}(300 \mu \mathrm{M}, 4 \mathrm{~h}),(\mathrm{C}) \mathrm{GSH}(1 \mathrm{mM})$, and (D) MAE $(100 \mu \mathrm{g} / \mathrm{mL})$. The quantitative analysis of fluorescence from three independent replicates was used by the Image-Pro Plus 6.0 software. Values with different letters above are significantly different, $p<0.05$, one-way ANOVA test.

pretreatment with MAE $(100 \mu \mathrm{g} / \mathrm{mL})$ significantly inhibited ROS and $\mathrm{O}_{2}^{-}$formations (Figure 3).

3.4. Effect of MAE on Protein Expressions of Nrf2 and MAPKs. Treatment with $\mathrm{H}_{2} \mathrm{O}_{2}$ for $4 \mathrm{~h}$ caused no change in Nrf2 expression but the HO-1 level was higher than that of the control. Nrf2 activation in HepG2 cells was induced by MAE, accompanied by the stimulation of HO-1. In parallel with this enhancement, GSH showed similar results with MAE, but less obvious change. Besides, $\mathrm{H}_{2} \mathrm{O}_{2}$ induced FOXO1 and PGC- $1 \alpha$ expressions and MAE repressed these alterations (Figure 4(a)). The phosphorylation of JNK was increased while no significant difference in p-p38 between the control and $\mathrm{H}_{2} \mathrm{O}_{2}$-induced cells. Again, MAE prevented the phosphorylation of JNK and meanwhile triggered the phosphorylation of p38, which may result in Nrf2 activation (Figure 4(b)). What is more, MAE also recovered GSH content as well as 

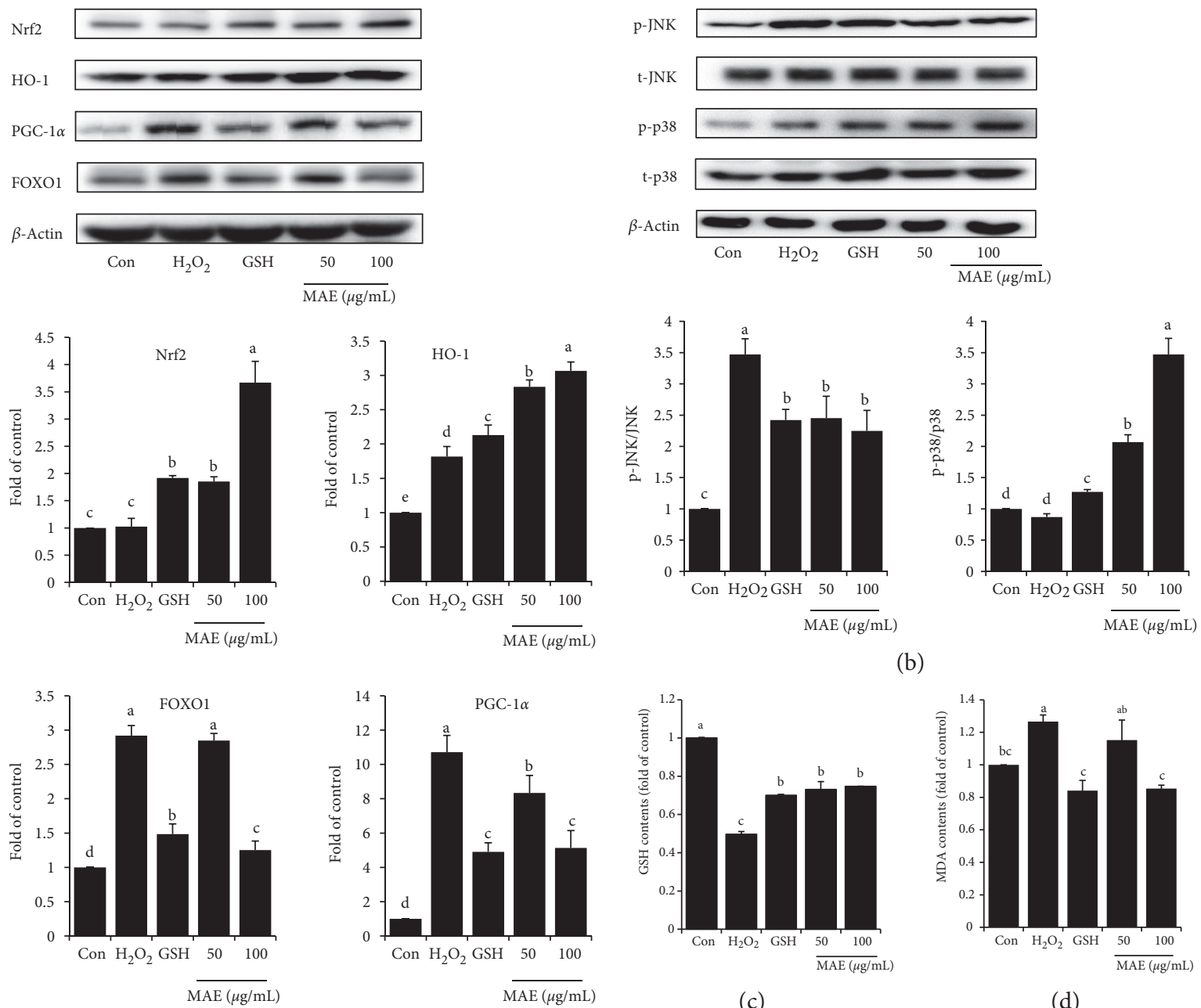

(b)

(a)

(c)

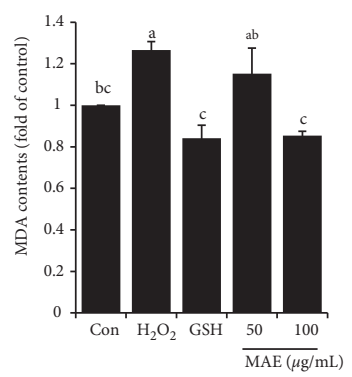

(d)

FIGURE 4: MAE treatment altered expressions of proteins associated with oxidative stress. (a) Protein levels of Nrf2, HO-1, PGC-1 $\alpha$, and FOXO1 in total cell extracts. Equal loading of Western blots was ensured by $\beta$-actin. (b) Protein levels of phosphorylated and total JNK and p38 in total cell extracts. Results were expressed as the ratio of phosphorylated/total protein levels. (c) GSH and (d) MDA contents determined by commercially available kits (NJJCBIO, China). Vertical lines represent standard deviations of three replicates. Values with different letters above are significantly different, $p<0.05$, one-way ANOVA test.

suppressed MDA content of HepG2 cells challenged by $\mathrm{H}_{2} \mathrm{O}_{2}$ (Figures 4(c) and 4(d)).

3.5. Effect of MAE on Nrf2, FOXO1, and PGC-1 $\alpha$ Transcriptional Activities in HepG2 Cells. In order to measure activities of transcription factors, cytoplasmic and nuclear fractionations from cell extracts were used for Western blotting analysis. In comparison with the normal cells, levels of nuclear FOXO1 and PGC- $1 \alpha$ were much higher in $\mathrm{H}_{2} \mathrm{O}_{2}-$ induced treatments, suggesting that their activities were enhanced. Furthermore, the Nrf2 level in the ratio of the nucleus to the cytoplasm was obviously decreased by $\mathrm{H}_{2} \mathrm{O}_{2}$. In contrast, decreased levels of FOXO1 and PGC- $1 \alpha$ as well as increased level of Nrf2 in the nucleus could be detected in cells pretreated with MAE, compared to those with the $\mathrm{H}_{2} \mathrm{O}_{2}$ treatment (Figure 5).

3.6. MAE Extended the Lifespan of C. elegans. Figure 6(a) demonstrated that exposure of worms to MAE increased lifespan compared to untreated ones. To test the protective ability against oxidative stress, we added paraquat into the medium, which could lead to a shortened life span. Our results also proved that the lifespan of $C$. elegans was shortened in the presence of paraquat, while MAE could partly reverse this damage, showing the longevity-promoting effect.

The nematode Caenorhabditis elegans contains autofluorescent lipofuscin granules, which can be quantitated by fluorescence spectroscopy. And this fluorescent material accumulated in animals with increasing age. Compared to controls, the paraquat-treated nematodes accumulated more lipofuscin at a greater rate. However, when paraquat-treated animals were exposed to $100 \mu \mathrm{g} / \mathrm{mL}$ MAE, levels of lipofuscin were suppressed more than a half (Figure 6(b)). In addition, MAE alleviated the increased content of MDA in worms that was stimulated by paraquat (Figure 6(c)). Response in C. elegans. Genes of SIR-2.1, DAF-16, AKT-1, 

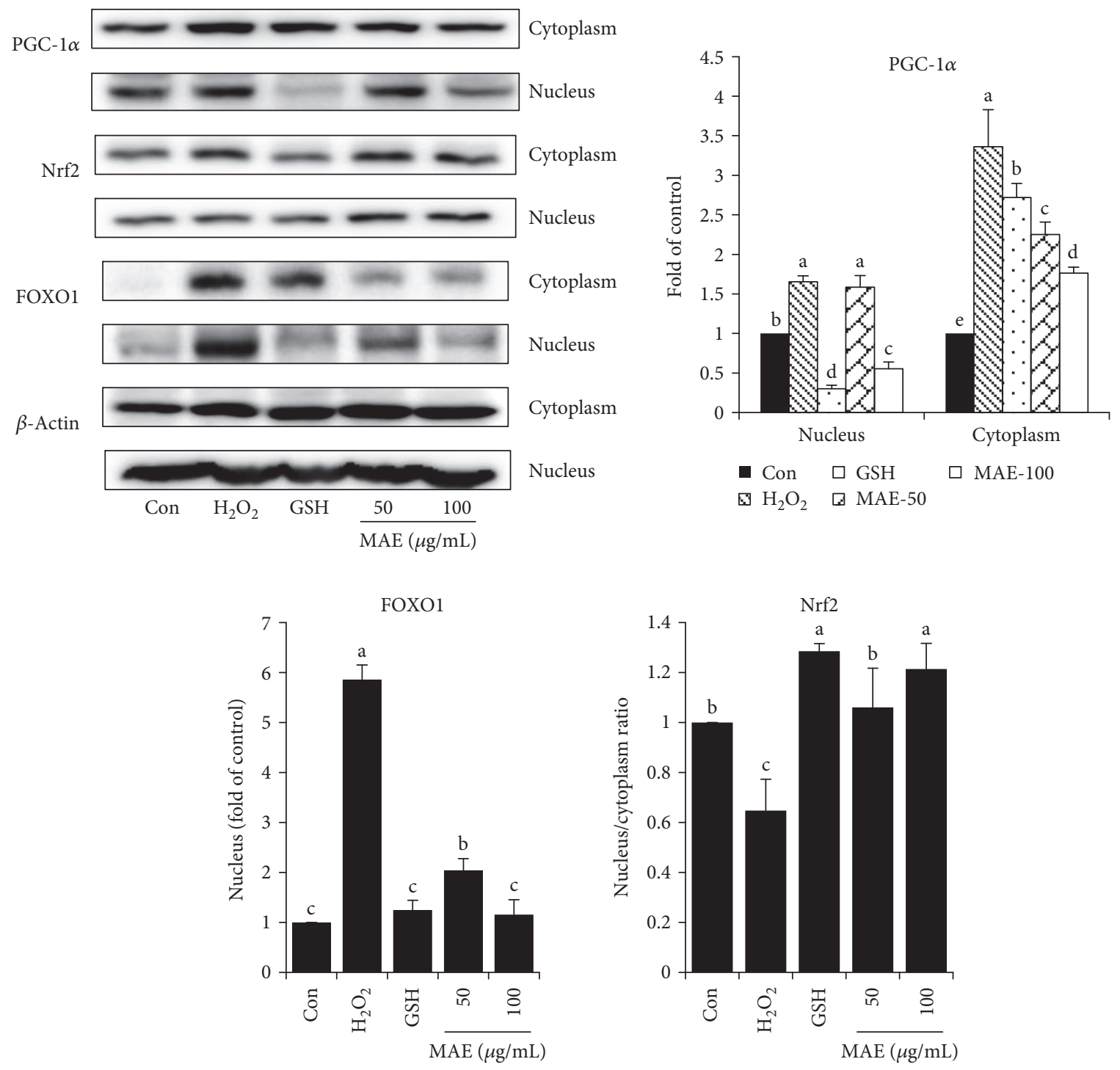

FIGURE 5: Effect of MAE on intracellular distribution of Nrf2, PGC-1 $\alpha$, and FOXO1 in HepG2 cells. The intensity of bands corresponding to $\mathrm{Nrf} 2$ in the nucleus was corrected by cytoplasmic protein levels to obtain relative measures of transcriptional activity among samples. FOXO1 expression level of the control in the cytoplasm is too low to be quantified. Vertical lines represent standard deviations of three replicates. Values with different letters above are significantly different, $p<0.05$, one-way ANOVA test.

PHA-4, RAGC-1, and AGE-1, which have a close relationship with aging or oxidative resistance, were all recovered with MAE treatment when worms suffered from paraquat. To confirm the molecular model of longevity in C. elegans, some mutants were used to evaluate the effects of MAE. In strains of CF1038 (daf-16 loss-of-function) and AY102 (pmk-1 partly loss-of-function), MAE failed to increase the survival rate under paraquat exposure (Figure 7(a)), in contrast to results obtained with N2 worms (Figure 6(a)). Furthermore, MAE also failed to suppress increased levels of lipofuscin in CF1038 strain (Figure 7(b)). mRNA levels of PMK-1 and SKN-1 were activated after exposure to paraquat, and MAE suppressed PMK-1 activation but enhanced stimulation of SKN-1 (Figure 6(d)), which was consistent with the results of GFP expressions in AY102 and SPC167 mutants (Figures $7(\mathrm{c})$ and $7(\mathrm{~d})$ ). These findings indicated that MAE might perform its protective activity by modulation of the expression of stress-response genes, such as DAF-16, PMK-1, and SKN-1.

\section{Discussion}

Anthocyanins are key components in the human diet due to their frequent presence in plants, particularly dark-colored fruits, vegetables, and pigmented grains. During the past decade, anthocyanins have drawn increasing attention because they possess a powerful health-promoting property. In this study, anthocyanins extracted from mulberry fruit revealed three main ingredients recognized as cyanidin-3glucoside, cyanidin-3-rutinoside, and pelargonidin-3-glucoside, which was consistent with previous research $[11,12]$ and accounted for more than $75 \%$ of the whole extract. 


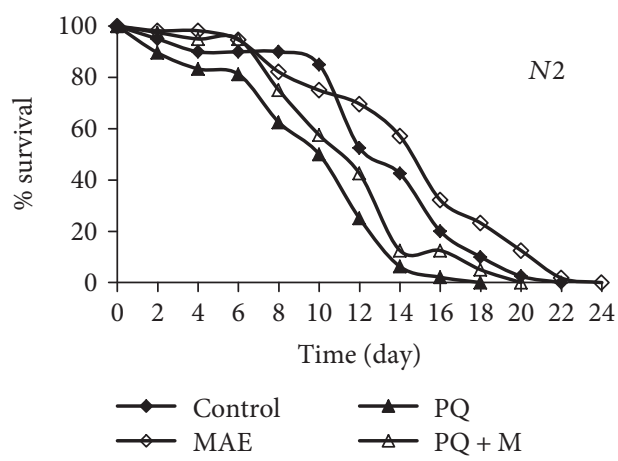

(a)
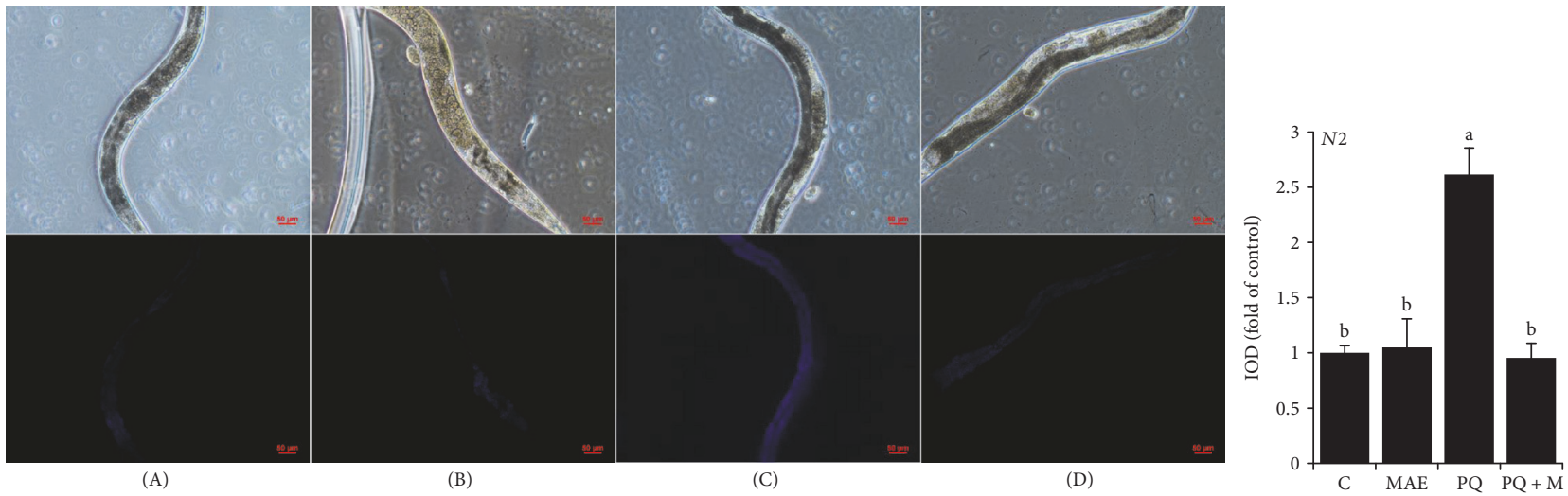

(b)

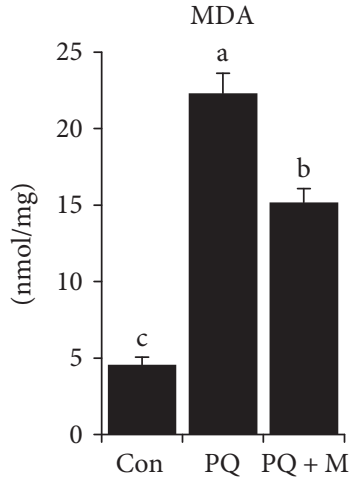

(c)

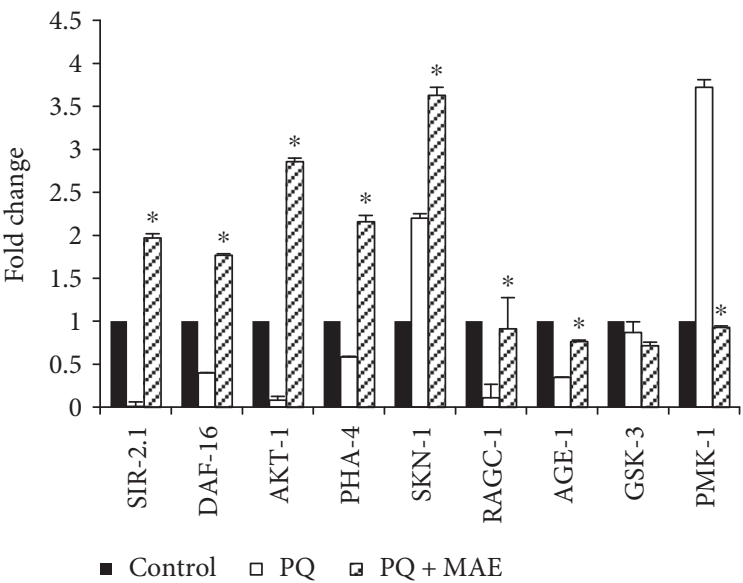

(d)

FIgURE 6: Protective effect of MAE on C. elegans under PQ exposure. (a) Lifespan of N2 under different conditions. (b) On the 10th day of adulthood, the intestinal autofluorescence of lipofuscin was analyzed. (A) control, (B) MAE, (C) paraquat (1 mM), and (D) paraquat in the presence of MAE. Densitometry analysis was performed using the Image-Pro Plus 6.0 software. (c) MDA contents determined by a commercially available kit (NJJCBIO, China). Values with different letters above are significantly different, $p<0.05$, one-way ANOVA test. (d) mRNA levels among control, paraquat $(1 \mathrm{mM})$, and paraquat with MAE. ${ }^{*} p<0.05$ versus paraquat.

Apart from direct antioxidative reactivity, compounds such as certain polyphenols and flavonoids may also activate some intracellular signalling pathways like the Nrf2 pathway, to prolong the cellular defense response. In the present study, the lower Nrf2 protein is transferred into the nucleus in $\mathrm{H}_{2} \mathrm{O}_{2}$-treated cells, although levels have no significant difference in total cell extracts. MAE incubation not only leads to translocation of Nrf2 from the cytosol to the nucleus but also increases total cellular Nrf2 content, contributing to HO-1 and GSH level increases. Besides, distinct enhancement of p38 phosphorylation was investigated in cells treated with MAE. Considering p38 MAPK is vital in immune response and involved in Nrf2 activation in several cells [27], it seems probably that MAE can activate, at least in part, the p38 MAPK pathway, which in turn promotes Nrf2 activity. 

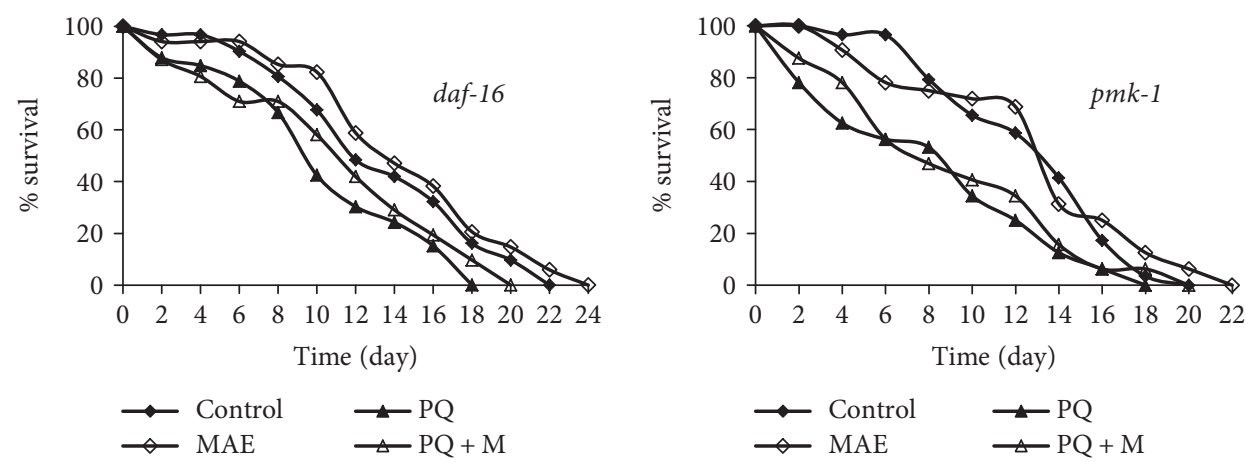

(a)
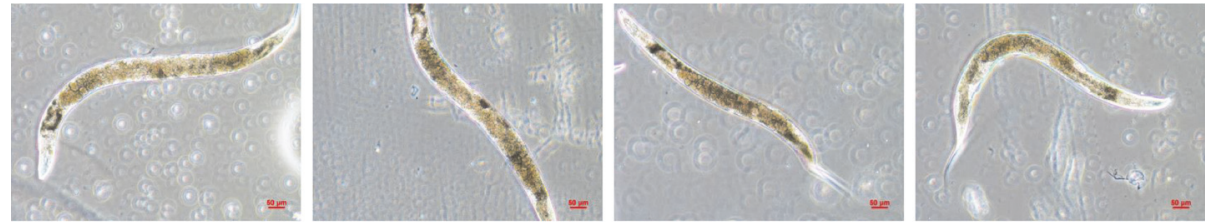

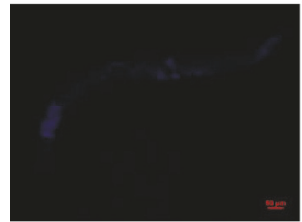

(A)
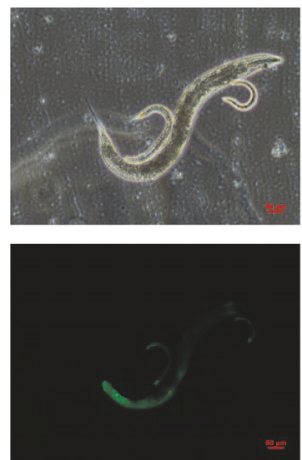

(A)
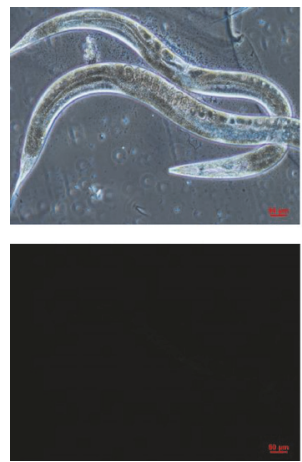

(A)

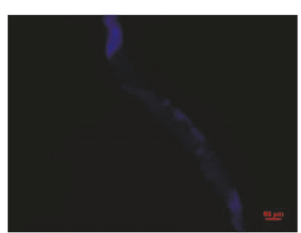

(B)
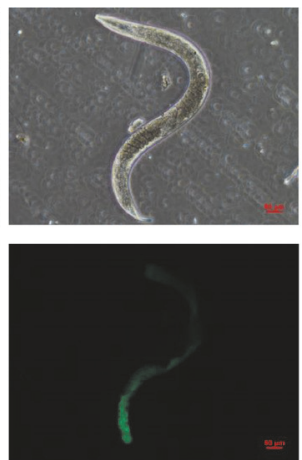

(B)
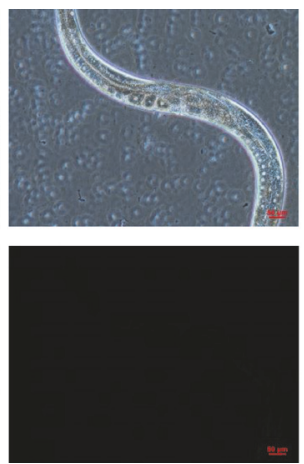

(B)

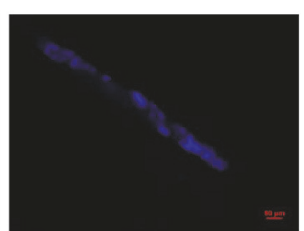

(C)

(b)
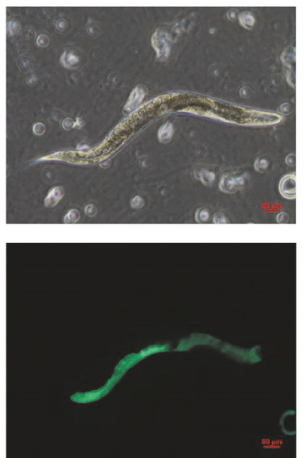

(C)

(c)
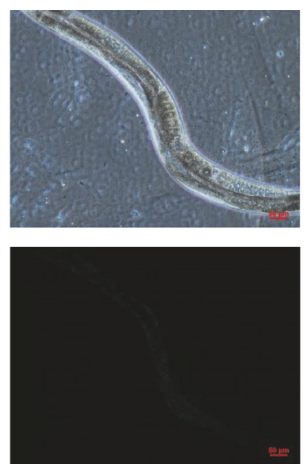

(C)

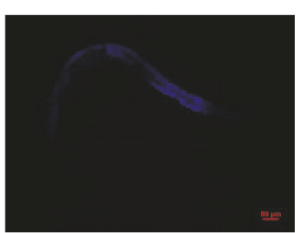

(D)
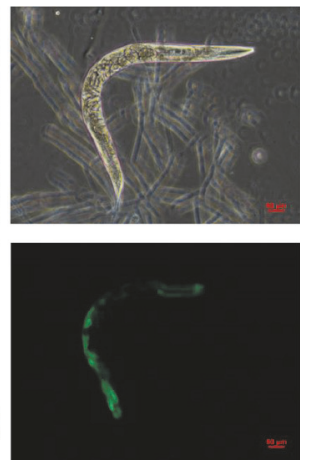

(D)
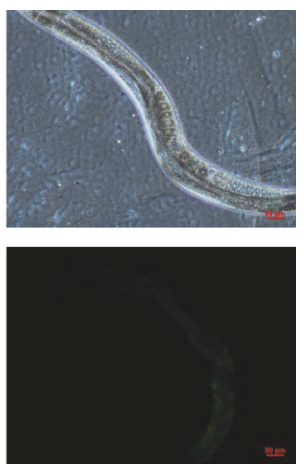

(D)

(d)

FIGURe 7: Continued. 

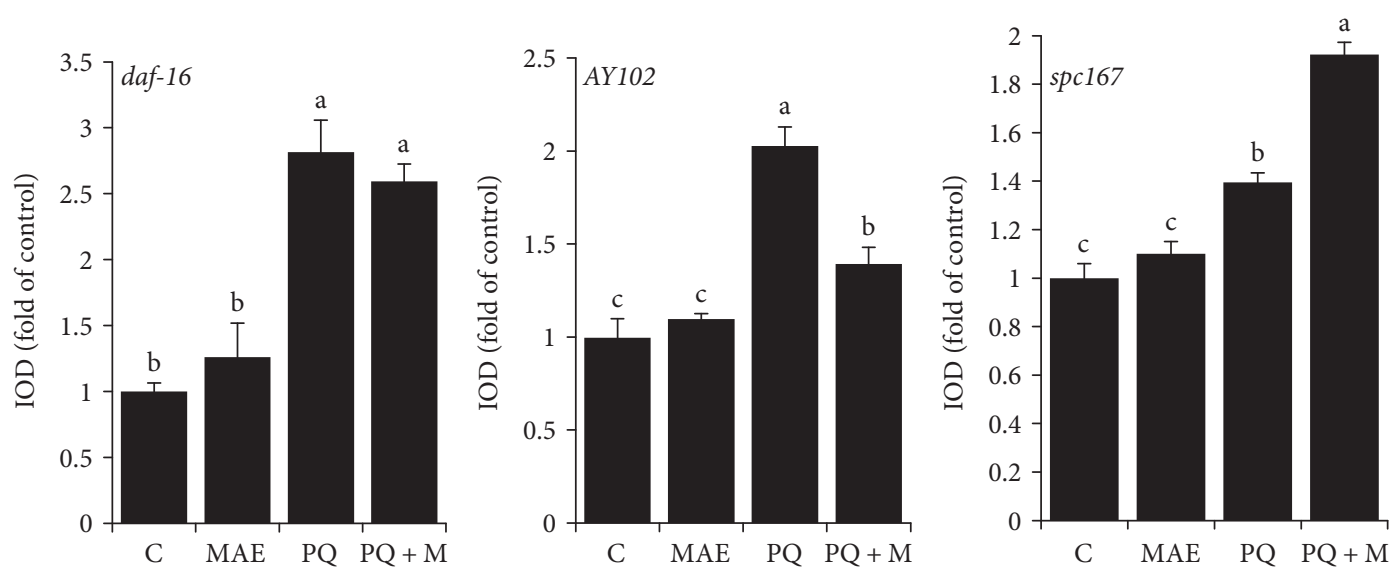

(e)

FIGURE 7: Effective assessment of MAE on oxidative protection in different mutants. (a) Lifespans of daf-16 and pmk-1. (b) Lipofuscin levels of daf-16 on the 10th day of adulthood. (c) PMK-1 expression in mutant AY102 worms. (d) SKN-1 activity was imaged for GFP expression indicative of SKN-1 activation of the gst-4p::gfp reporter in mutant SPC167 worms. (A) control, (B) MAE, (C) paraquat (1 mM), and (D) paraquat in the presence of MAE. (e) The quantitative analysis of fluorescence. Densitometry analysis was performed using the Image-Pro Plus 6.0 software. Values with different letters above are significantly different, $p<0.05$, one-way ANOVA test.

These results provide further evidence indicating that MAE enhances HO-1 expression by mediating Nrf2 translocation via p38 MAPK phosphorylation stimulation to scavenge $\mathrm{H}_{2} \mathrm{O}_{2}$-induced excessive free radicals.

Oxidative stress is the main contributor to diabetic complications, and $\mathrm{H}_{2} \mathrm{O}_{2}$ can result in ROS generation in the liver, which in turn causes hepatic insulin resistance $[28,29]$. Studies have shown that cyanidin-3-glucoside isolated from mulberry fruit restrains high-glucose $/ \mathrm{H}_{2} \mathrm{O}_{2}$ induced pancreatic $\beta$-cell death $[30,31]$. In concurrence with previous studies, decreases in glucose consumption and uptake were observed in $\mathrm{H}_{2} \mathrm{O}_{2}$-induced HepG2 cells, meaning insulin resistance was formed. MAE treatments exhibit an evident increase in glucose consumption and glucose uptake in model cells, which means MAE can mitigate these adverse effects caused by $\mathrm{H}_{2} \mathrm{O}_{2}$. In the liver, glucose-6-phosphatase (G6Pase) and phosphoenolpyruvate carboxykinase (PEPCK) participate in committed steps of gluconeogenesis, playing vital roles in glucose homeostasis, and FOXO1 can regulate their expression levels by directly binding to their target DNA sequence [32]. Expression of PGC- $1 \alpha$ and its target genes is implicated in hepatic gluconeogenesis, oxidative phosphorylation, and mitochondrial biogenesis [33]. What is more, there is also an interaction between PGC- $1 \alpha$ and FOXO1 in the performance of insulin-regulated gluconeogenesis. Higher FOXO1 and PGC- $1 \alpha$ expressions and transcriptional activities are investigated in $\mathrm{H}_{2} \mathrm{O}_{2}$-induced HepG2 cells while impaired by MAE. These changes may lead to PEPCK and G6Pase downregulation, causing a decrease in gluconeogenesis, and can result in antidiabetic.

JNK can be stimulated by ROS and cause insulin receptor substrates 1 (IRS1) serine phosphorylation to impair insulin signal transduction. Besides, activated JNK promotes FOXO1 activity by facilitating its movement to the nucleus [34]. A recent study has revealed that nuclear translocation of FOXO1 is rapidly induced by $\mathrm{H}_{2} \mathrm{O}_{2}$ but blocked by the JNK inhibitor [35]. On the contrary to p38, JNK upregulation is observed in $\mathrm{H}_{2} \mathrm{O}_{2}$-induced HepG2 cells while it is inhibited by MAE treatment, contributing to suppression of FOXO1 activity in response to the oxidative stress cells. Guo et al. reported that cyanidin-3-glucoside protected 3T3-L1 adipocytes against $\mathrm{H}_{2} \mathrm{O}_{2}$-induced insulin resistance by impairing JNK activation [36]. They also showed that beneficial effects of $\mathrm{C} 3 \mathrm{G}$ in $\mathrm{db} / \mathrm{db}$ mice were related to its inhibition on the JNK/FOXO1 pathway [37]. Given these findings along with our present data, we strongly suggest that these beneficial effects of MAE on insulin resistance improvement can be due to restrained upregulation of JNK, FOXO1, and PGC- $1 \alpha$ in $\mathrm{H}_{2} \mathrm{O}_{2}$-induced HepG2 cells.

C. elegans, a highly advantageous organism, plays an important role in genetic and other in vivo research. To investigate whether the protective effect exhibited by MAE is evolutionarily conserved, we selected C. elegans for further experiments. Under the condition of oxidative stress, MAE as a powerful antioxidant has the capacity on cellular damage alleviation, explaining the extended lifespan of $C$. elegans treated with paraquat in the presence of MAE. Peixoto et al. [38] have demonstrated that stress resistance is increased and an aging-related marker is retarded in C. elegans by an anthocyanin-rich extract of acai, which is consistent with our results. AKT-1 and DAF-16/FOXO are vital factors in the insulin/IGF-1 pathway, associating with longevity in C. elegans. Chen et al. indicated that purple wheat that was rich in anthocyanin exhibited a lifespan-prolonging effect and was partly dependent on the activation of the transcription factor DAF-16/FOXO [39]. In this study, MAE also fails to extend the lifespan and lipofuscin accumulation in daf-16 mutant, suggesting that DAF-16/FOXO is one of the targets of MAE to play an antioxidant activity. PMK-1/p38 has been found to phosphorylate SKN-1 directly to activate its activity, and the p38 MAPK pathway is highly related to oxidative stress response [40]. SKN-1, the C. elegans ortholog 
mammalian protein of $\mathrm{Nrf} 2$, participates in many regulatory pathways involved in different stresses, and it is also modulated by the insulin-like/IGF-1 pathway for the promotion of longevity. AY102 animals were developed by introducing the acEx102 extrachromosomal array into KU25 animals, resulting in intestinal PMK-1::GFP expression [41]. Because of pmk-1 deletion, AY102 animals were more susceptible to oxidative stress and MAE could not recover such damages, indicating that MAE may modulate PMK-1 activity in other tissues besides those of the intestine. GFP levels can be stimulated under some stresses in SPC 167 worms [42], and our findings show that oxidative stress induces SKN-1 while MAE enhances such augment to prolong defensive reaction. However, it is necessary for more research to figure out the exact mechanism.

In conclusion, using in vitro studies, we suggest that MAE significantly mitigates $\mathrm{H}_{2} \mathrm{O}_{2}$-induced cytotoxicity by activating the MAPK-Nrf2 pathway in HepG2 cells. Additionally, MAE improves hepatic insulin resistance through inhibiting PGC- $1 \alpha$ and FOXO1 transcriptional activity to decrease gluconeogenesis as well as suppressing JNK phosphorylation to enhance insulin signalling transduction. In vivo studies, we present evidence that MAE also extends the lifespan of $C$. elegans by activating DAF-16/FOXO, SKN-1/Nrf2, PMK-1/p38, and their downstream targets that are related to longevity and stress. These findings provide some new underlying mechanisms of mulberry anthocyanins on cytoprotection and antiaging, implying that MAE may serve as a strategy to help improve human health.

\section{Abbreviations}

MAE: Mulberry anthocyanin extract

IR: Insulin resistance

Con: Control

GSH: Glutathione

Nrf2: $\quad$ Nuclear factor erythroid 2-related factor 2

JNK: c-Jun N-terminal kinase

MAPKs: Mitogen-activated protein kinases

FOXO1: Forkhead box protein $\mathrm{O} 1$

PGC- $1 \alpha$ : PPAR $\gamma$ coactivator $1 \alpha$

ROS: $\quad$ Reactive oxygen species

HO-1: Heme oxygenase-1

$\mathrm{H}_{2} \mathrm{O}_{2}$ : Hydrogen peroxide

PQ: $\quad$ Paraquat

MDA: Malondialdehyde.

\section{Conflicts of Interest}

The authors have declared no conflict of interest.

\section{Acknowledgments}

This work was supported by grants from Zhejiang Provincial Natural Science Foundation of China (no. LZ14C200001). Some strains were kindly provided by Dayong Wang (Southeast University, China).

\section{References}

[1] W. Zhu, Q. Jia, Y. Wang, Y. Zhang, and M. Xia, "The anthocyanin cyanidin-3-O- $\beta$-glucoside, a flavonoid, increases hepatic glutathione synthesis and protects hepatocytes against reactive oxygen species during hyperglycemia: involvement of a cAMP-PKA-dependent signaling pathway," Free Radical Biology and Medicine, vol. 52, no. 2, pp. 314-327, 2012.

[2] H. Guo and W. Ling, "The update of anthocyanins on obesity and type 2 diabetes: experimental evidence and clinical perspectives," Reviews in Endocrine \& Metabolic Disorders, vol. 16, no. 1, pp. 1-13, 2015.

[3] A. T. Dinkova-Kostova and A. Y. Abramov, "The emerging role of Nrf2 in mitochondrial function," Free Radical Biology and Medicine, vol. 88, Part B, pp. 179-188, 2015.

[4] M. S. Lee, B. Lee, K. E. Park et al., "Dieckol enhances the expression of antioxidant and detoxifying enzymes by the activation of Nrf2-MAPK signalling pathway in HepG2 cells," Food Chemistry, vol. 174, pp. 538-546, 2015.

[5] S. W. Ryter, L. E. Otterbein, D. Morse, and A. M. Choi, "Heme oxygenase/carbon monoxide signaling pathways: regulation and functional significance," Molecular and Cellular Biochemistry, vol. 234, no. 1, pp. 249-263, 2002.

[6] C. C. Franklin, D. S. Backos, I. Mohar, C. C. White, H. J. Forman, and T. J. Kavanagh, "Structure, function, and posttranslational regulation of the catalytic and modifier subunits of glutamate cysteine ligase," Molecular Aspects of Medicine, vol. 30, no. 1, pp. 86-98, 2009.

[7] P. Nioi and J. D. Hayes, "Contribution of NAD (P) H: quinone oxidoreductase 1 to protection against carcinogenesis, and regulation of its gene by the Nrf2 basic-region leucine zipper and the arylhydrocarbon receptor basic helix-loophelix transcription factors," Mutation Research, Fundamental and Molecular Mechanisms of Mutagenesis, vol. 555, no. 1, pp. 149-171, 2004.

[8] P. S. Wu, J. H. Yen, M. C. Kou, and M. J. Wu, "Luteolin and apigenin attenuate 4-hydroxy-2-nonenal-mediated cell death through modulation of UPR, Nrf2-ARE and MAPK pathways in PC12 cells," PLoS One, vol. 10, article e0130599, no. 6, 2015.

[9] C. Tsai, C. Lin, and Y. Wang, "Carnosic acid induces the NAD (P) $\mathrm{H}$ : quinone oxidoreductase 1 expression in rat clone 9 cells through the p38/nuclear factor erythroid-2 related factor 2 pathway," The Journal of Nutrition, vol. 141, no. 12, pp. 2119-2125, 2011.

[10] P. Shih, S. Hwang, C. Yeh, and G. Yen, "Synergistic effect of cyanidin and PPAR agonist against nonalcoholic steatohepatitis-mediated oxidative stress-induced cytotoxicity through MAPK and Nrf2 transduction pathways," Journal of Agricultural and Food Chemistry, vol. 60, no. 11, pp. 2924-2933, 2012.

[11] A. M. Pawlowska, W. Oleszek, and A. Braca, "Quali-quantitative analyses of flavonoids of Morus nigra L. and Morus alba L.(Moraceae) fruits," Journal of Agricultural and Food Chemistry, vol. 56, no. 9, pp. 3377-3380, 2008.

[12] H. Huang, T. Ou, and C. Wang, "Mulberry (sang shen zi) and its bioactive compounds, the chemoprevention effects and molecular mechanisms in vitro and in vivo," Journal of Traditional and Complementary Medicine, vol. 3, no. 1, pp. 7-15, 2013.

[13] H. Wang, G. Cao, and R. L. Prior, "Oxygen radical absorbing capacity of anthocyanins," Journal of Agricultural and Food Chemistry, vol. 45, no. 2, pp. 304-309, 1997. 
[14] J. Cheng, X. Liu, Z. Chen, Y. Zhang, and Y. Zhang, "Mulberry anthocyanin biotransformation by intestinal probiotics," Food Chemistry, vol. 213, pp. 721-727, 2016.

[15] N. M. Hassimotto, M. I. Genovese, and F. M. Lajolo, "Absorption and metabolism of cyanidin-3-glucoside and cyanidin-3-rutinoside extracted from wild mulberry (Morus nigra L.) in rats," Nutrition Research, vol. 28, no. 3, pp. 198-207, 2008.

[16] Y. Li, Z. Yang, S. Jia, and K. Yuan, "Protective effect and mechanism of action of mulberry marc anthocyanins on carbon tetrachloride-induced liver fibrosis in rats," Journal of Functional Foods, vol. 24, pp. 595-601, 2016.

[17] S. T. Raman, A. K. Ganeshan, C. Chen et al., "In vitro and in vivo antioxidant activity of flavonoid extracted from mulberry fruit (Morus alba L.)," Pharmacognosy Magazine, vol. 12, no. 46, pp. 128-133, 2016.

[18] T. Wu, J. Yin, G. Zhang, H. Long, and X. Zheng, "Mulberry and cherry anthocyanin consumption prevents oxidative stress and inflammation in diet-induced obese mice," Molecular Nutrition \& Food Research, vol. 60, no. 3, pp. 687-694, 2016.

[19] F. Yan, J. Zhang, L. Zhang, and X. Zheng, "Mulberry anthocyanin extract regulates glucose metabolism by promotion of glycogen synthesis and reduction of gluconeogenesis in human HepG2 cells," Food \& Function, vol. 7, no. 1, pp. 425-433, 2016.

[20] J. Yin, R. Hu, M. Chen et al., "Effects of berberine on glucose metabolism in vitro," Metabolism, vol. 51, no. 11, pp. 14391443, 2002.

[21] Y. P. Hwang, J. H. Choi, E. H. Han et al., "Purple sweet potato anthocyanins attenuate hepatic lipid accumulation through activating adenosine monophosphate-activated protein kinase in human HepG2 cells and obese mice," Nutrition Research, vol. 31, no. 12, pp. 896-906, 2011.

[22] W. Liu, X. Lu, G. He et al., "Cytosolic protection against ultraviolet induced DNA damage by blueberry anthocyanins and anthocyanidins in hepatocarcinoma HepG2 cells," Biotechnology Letters, vol. 35, no. 4, pp. 491-498, 2013.

[23] Y. P. Hwang, J. H. Choi, J. M. Choi, Y. C. Chung, and H. G. Jeong, "Protective mechanisms of anthocyanins from purple sweet potato against tert-butyl hydroperoxide-induced hepatotoxicity," Food and Chemical Toxicology, vol. 49, no. 9, pp. 2081-2089, 2011.

[24] Q. Lv, M. Si, Y. Yan et al., "Effects of phenolic-rich litchi (Litchi chinensis Sonn.) pulp extracts on glucose consumption in human HepG2 cells," Journal of Functional Foods, vol. 7, pp. 621-629, 2014.

[25] R. G. O'Neil, L. Wu, and N. Mullani, "Uptake of a fluorescent deoxyglucose analog (2-NBDG) in tumor cells," Molecular Imaging and Biology, vol. 7, no. 6, pp. 388-392, 2005.

[26] V. H. Liao, C. Yu, Y. Chu, W. Li, Y. C. Hsieh, and T. T. Wang, "Curcumin-mediated lifespan extension in Caenorhabditis elegans," Mechanisms of Ageing and Development, vol. 132, no. 10, pp. 480-487, 2011.

[27] G. L. Johnson and R. Lapadat, "Mitogen-activated protein kinase pathways mediated by ERK, JNK, and p38 protein kinases," Science, vol. 298, no. 5600, pp. 1911-1912, 2002.

[28] J. L. Evans, I. D. Goldfine, B. A. Maddux, and G. M. Grodsky, "Oxidative stress and stress-activated signaling pathways: a unifying hypothesis of type 2 diabetes," Endocrine Reviews, vol. 23, no. 5, pp. 599-622, 2002.
[29] J. L. Rains and S. K. Jain, "Oxidative stress, insulin signaling, and diabetes," Free Radical Biology and Medicine, vol. 50, no. 5, pp. 567-575, 2011.

[30] J. S. Lee, Y. R. Kim, J. M. Park, Y. E. Kim, N. I. Baek, and E. K. Hong, "Cyanidin-3-glucoside isolated from mulberry fruits protects pancreatic $\beta$-cells against glucotoxicityinduced apoptosis," Molecular Medicine Reports, vol. 11, no. 4, pp. 2723-2728, 2015.

[31] J. S. Lee, Y. R. Kim, I. G. Song et al., "Cyanidin-3-glucoside isolated from mulberry fruit protects pancreatic beta-cells against oxidative stress-induced apoptosis," International Journal of Molecular Medicine, vol. 35, no. 2, pp. 405-412, 2015.

[32] K. Sekine, Y. R. Chen, N. Kojima, K. Ogata, A. Fukamizu, and A. Miyajima, "Foxo1 links insulin signaling to $\mathrm{C} / \mathrm{EBP} \alpha$ and regulates gluconeogenesis during liver development," The EMBO Journal, vol. 26, no. 15, pp. 3607-3615, 2007.

[33] H. Oberkofler, V. Linnemayr, R. Weitgasser et al., "Complex haplotypes of the PGC- $1 \alpha$ gene are associated with carbohydrate metabolism and type 2 diabetes," Diabetes, vol. 53, no. 5, pp. 1385-1393, 2004.

[34] M. A. Essers, S. Weijzen, A. M. de Vries-Smits et al., "FOXO transcription factor activation by oxidative stress mediated by the small GTPase Ral and JNK," The EMBO Journal, vol. 23, no. 24, pp. 4802-4812, 2004.

[35] B. Shen, L. Chao, and J. Chao, "Pivotal role of JNK-dependent FOXO1 activation in downregulation of kallistatin expression by oxidative stress," American Journal of Physiology - Heart and Circulatory Physiology, vol. 298, no. 3, pp. H1048H1054, 2010.

[36] H. Guo, W. Ling, Q. Wang, C. Liu, Y. Hu, and M. Xia, "Cyanidin 3-glucoside protects 3T3-L1 adipocytes against $\mathrm{H}_{2} \mathrm{O}_{2}$-or TNF- $\alpha$-induced insulin resistance by inhibiting c-Jun $\mathrm{NH}_{2}$ terminal kinase activation," Biochemical Pharmacology, vol. 75, no. 6, pp. 1393-1401, 2008.

[37] H. Guo, M. Xia, T. Zou, W. Ling, R. Zhong, and W. Zhang, "Cyanidin 3-glucoside attenuates obesity-associated insulin resistance and hepatic steatosis in high-fat diet-fed and $\mathrm{db} / \mathrm{db}$ mice via the transcription factor FoxO1," The Journal of Nutritional Biochemistry, vol. 23, no. 4, pp. 349-360, 2012.

[38] H. Peixoto, M. Roxo, S. Krstin, T. Röhrig, E. Richling, and M. Wink, "An anthocyanin-rich extract of acai (Euterpe precatoria Mart.) increases stress resistance and retards aging-related markers in Caenorhabditis elegans," Journal of Agricultural and Food Chemistry, vol. 64, no. 6, pp. 1283-1290, 2016.

[39] W. Chen, D. Müller, E. Richling, and M. Wink, “Anthocyaninrich purple wheat prolongs the life span of Caenorhabditis elegans probably by activating the DAF-16/FOXO transcription factor," Journal of Agricultural and Food Chemistry, vol. 61, no. 12, pp. 3047-3053, 2013.

[40] T. K. Blackwell, M. J. Steinbaugh, J. M. Hourihan, C. Y. Ewald, and M. Isik, "SKN-1/Nrf, stress responses, and aging in Caenorhabditis elegans," Free Radical Biology and Medicine, vol. 88, Part B, pp. 290-301, 2015.

[41] D. D. Bolz, J.L. Tenor, and A. Aballay, "A conserved PMK-1/p38 MAPK is required in Caenorhabditis elegans tissue-specific immune response to Yersinia pestis infection," Journal of Biological Chemistry, vol. 285, no. 14, pp. 10832-10840, 2010.

[42] J. Paek, J. Y. Lo, S. D. Narasimhan et al., "Mitochondrial SKN-1/Nrf mediates a conserved starvation response," Cell Metabolism, vol. 16, no. 4, pp. 526-537, 2012. 


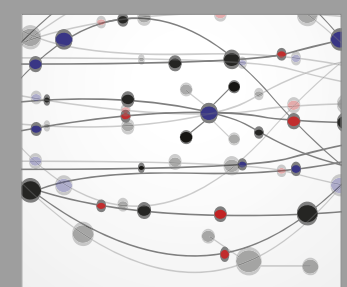

The Scientific World Journal
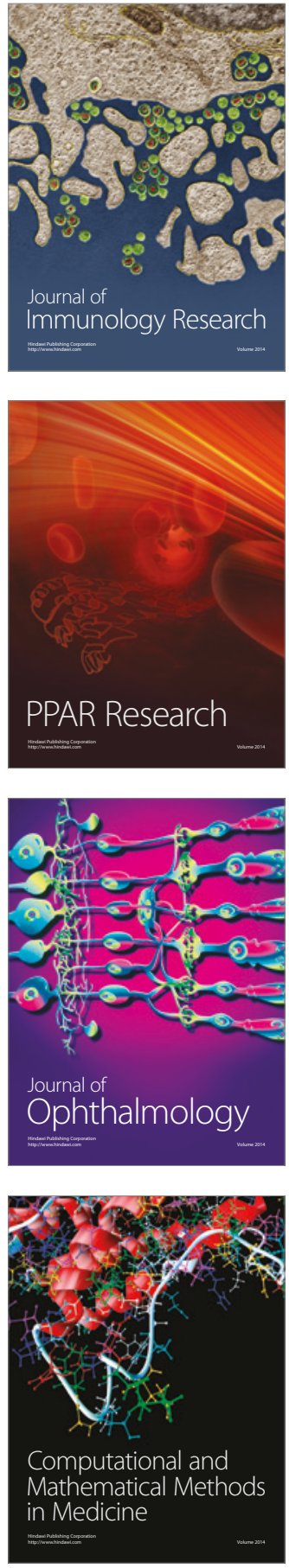

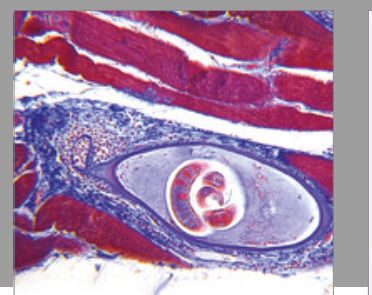

Gastroenterology Research and Practice
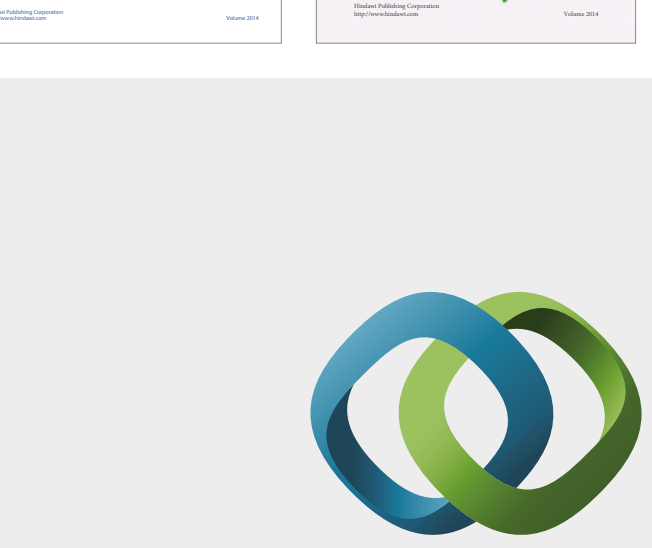

\section{Hindawi}

Submit your manuscripts at

https://www.hindawi.com
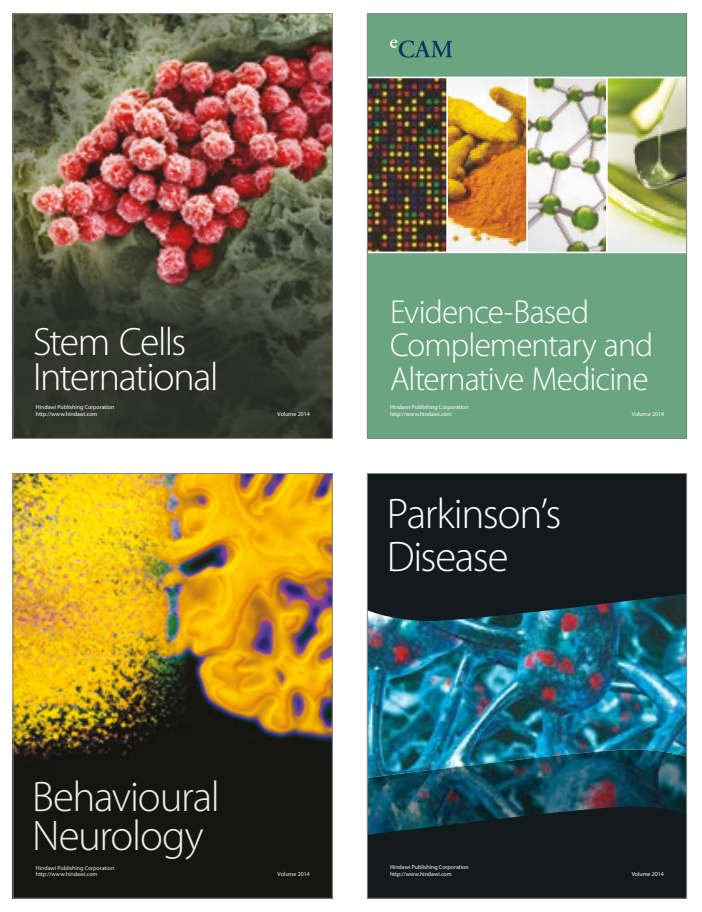
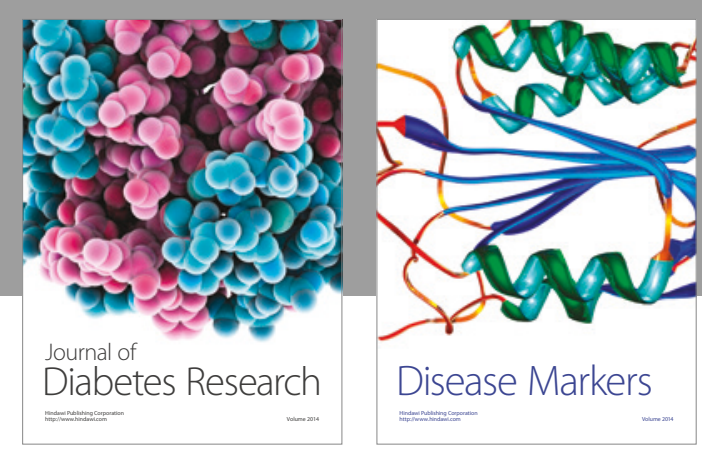

Disease Markers
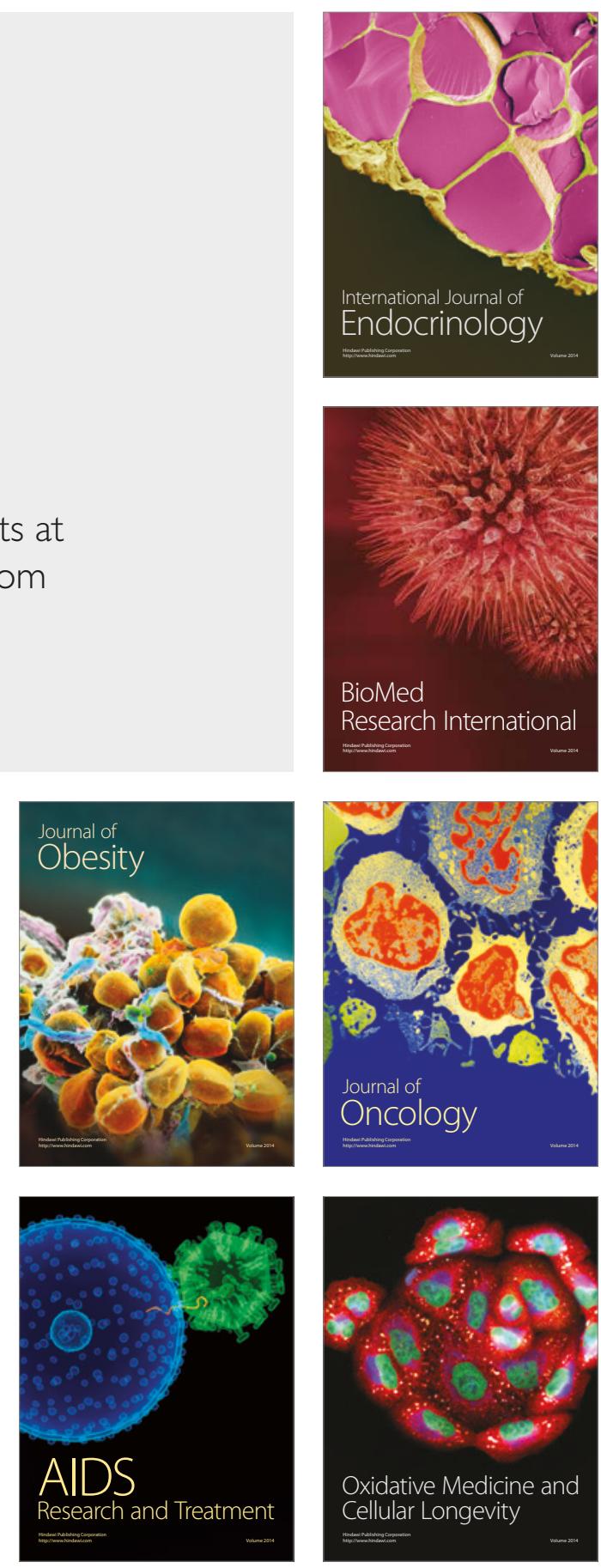